\title{
Role of Inflammation in Suicide: From Mechanisms to Treatment
}

\author{
Lena Brundin ${ }^{1}$, Elena $Y$ Bryleva $^{1}$ and Keerthi Thirtamara Rajamani ${ }^{\star, 1}$ \\ ${ }^{1}$ Laboratory of Behavioral Medicine, Center for Neurodegenerative Science, Van Andel Research Institute, Grand Rapids, \\ MI, USA
}

Suicidal behavior is complex and manifests because of a confluence of diverse factors. One such factor involves dysregulation of the immune system, which has been linked to the pathophysiology of suicidal behavior. This review will provide a brief description of suicidality and discuss the contribution of upstream and downstream factors in the etiology of suicidal behavior, within the contextual framework of inflammation. The contribution of inflammatory conditions such as traumatic brain injury, autoimmune disorders, and infections to neuropsychiatric symptoms and suicidality is only beginning to be explored. We will summarize studies of inflammation in the etiology of suicide, and provide a neurobiological basis for different mechanisms by which inflammation might contribute to the pathophysiology. Finally, we will review treatments that affect upstream and downstream pathways related to inflammation in suicidality.

Neuropsychopharmacology Reviews (2017) 42, 27I-283; doi: 10.1 038/npp.20 16.1 I6; published online 27 July 2016

\section{INTRODUCTION}

Death by suicide is the second leading cause of mortality among the 15-29 age group worldwide (WHO, 2012). It is estimated that 40000 people die of suicide every year in the United States, and the global death toll is estimated to be at $\sim 800000$ (WHO, 2014). The World Health Organization predicts close to one million deaths by the year 2030, contributing to a projected $1.4 \%$ of all deaths worldwide (World Health Organization, 2011). The actual numbers may be far higher, as suicidal deaths tend to be typically under reported because of societal taboos and criminalization of suicide in certain societies.

Suicide attempts may, likewise, be grossly underestimated because of poor reporting and insufficient data collection. Twenty or more suicide attempts occur for every one death by suicide, suggesting that suicide attempts are more frequent than suicide itself (Bertolote et al, 2010). Suicide attempts are currently the best predictor of completed suicide, which indicates that proper reporting and close monitoring of the individuals who attempt suicide may serve to prevent future suicides. To this effect, Da Cruz et al determined that over $40 \%$ of individuals who died by suicide visited the emergency department at least once in the

\footnotetext{
${ }^{*}$ Correspondence: Dr K Thirtamara Rajamani, Department of Behavioral Medicine, Laboratory of Behavioral Medicine, Center for Neurodegenerative Science, Van Andel Research Institute, Grand Rapids, Ml 49503, USA, Tel: +1 616234 5321, Fax: +1 616234 5180, E-mail: Keerthi. rajamani@vai.org

Received 16 March 2016; revised 31 May 2016; accepted 28 June 2016; accepted article preview online 5 July 2016
}

12 months before death; with $28 \%$ of them visiting on more than three occasions. Death by suicide followed soon after the last emergency department visit in the group of frequent attempters compared with other attenders (Da Cruz et al, 2011). This critically underscores the insufficiency of existing methods of suicide risk assessment, demonstrated by failure to identify high-risk individuals despite repeated visits to the emergency department before death.

There are also some consistent gender differences in suicidal behavior that are important to note. In many countries, including the United States, male-completed suicides outnumber females-completed ones with a ratio $\sim 3: 1$, although women are more likely to experience suicidal ideation to a higher degree than men (SAMHSA, 2013). Men are also likely to employ more violent methods of suicide than women (Canetto and Sakinofsky, 1998). Both suicide deaths and attempts are acts of extreme psychological despair, and constitute a profound emotional burden to both the family and relatives of the victims. In essence, there is a great need to develop diagnostic methods, which include behavioral and biological indicators for reliable and timely identification of risk factors that may lead to suicidal behavior.

\section{CLINICAL ASPECTS OF SUICIDALITY}

Suicide is defined as an intentional act of taking one's life by engaging in self-directed injurious behavior. Suicidal ideation and suicide attempts are suicidal behavior that may manifest as standalone events or precipitate a completed suicide (Crosby et al, 2011). Several theories have been 
proposed to model suicide risk, each taking into account etiological and phenotypic variability that is associated with suicide. They are categorized into risk factors that predispose (distal factors) and precipitate suicidal event (proximal factors). Proximal factors are typically associated with neuropsychiatric pathology and may be precipitated by stressful life events (Mann, 2003). Psychiatric disorders and the risk for suicidal behavior has been a topic of intense study given that $\sim 90 \%$ of suicide completers are diagnosed with some form of psychiatric illness including major depressive disorder (MDD) and substance abuse disorders (ArsenaultLapierre et al, 2004). Behavioral traits such as impulsivity and aggressive behavior may also contribute to the risk of suicidal behavior, specifically in adolescents or young adults. These traits are often co-morbid with different psychiatric disorders such as bipolar disorders and substance abuse disorders (Brent et al, 1994; Cuomo et al, 2008; McGirr et al, 2008).

Familial transmission and early life adversity (ELA) are distal events associated with suicide risk (Mann, 2003; Moscicki, 1994). Physical or sexual abuse and parental neglect are significantly associated with suicidal risk (Brezo et al, 2008). The association between ELA and suicide risk in these individuals is strongly supported by the changes in several downstream factors, including epigenetic changes, hypothalamic-pituitary-adrenal (HPA) axis activation and neuronal plasticity, informed to a large extent by animal studies and post-mortem studies (Labonte et al, 2013; Labonte et al, 2012; McGowan et al, 2009; Roth et al, 2011).

Family history of suicidal behavior has also been identified as a risk factor. In a registry-based study, Tidemalm et al (2011) assessed suicides in probands of individuals who died by suicide, and determined that the risk does run in families and is influenced by both genetic and shared environmental factors. Given that suicidal behavior is strongly associated with psychiatric disorders, Brent et al examined suicidal behavior and psychopathology among probands of adolescent suicide victims. They observed that the rates of suicide attempts were higher in relatives of adolescent suicide victims even after controlling for familial rates of psychopathology, suggesting that familial transmission of suicide is discrete from psychopathology (Brent et al, 1996).

Substance abuse is also considered a risk factor for suicidal behavior. The risk for suicide is much higher in individuals with substance abuse disorder compared with general population (Wilcox et al, 2004). However, the majority of individuals with substance abuse issues are often diagnosed with other psychiatric conditions, a confounding factor which must be kept in perspective (Treatment. CfSA, 2009). Conditions, such as early childhood trauma and posttraumatic stress disorders (PTSDs), often co-occur with substance abuse and their ability to confer suicide risk has also been explored. Roy (2003) assessed the association between childhood trauma and suicide attempts in individuals with substance abuse and determined that in these individuals, suicide attempts were associated with childhood trauma. Furthermore, Price et al (2004) found that drug dependence was associated with PTSD and suicidal behavior in a cohort of Vietnam veterans assessed over a period of 25 years. Overall, suicidal behavior may manifest as a consequence of interaction between early life events, traits such as aggression and impulsivity, and psychiatric illness.

\section{INFLAMMATION AND SYMPTOMS OF SUICIDALITY}

Aberrations in inflammatory cytokines have been reported in several neuropsychiatric conditions, including MDD, schizophrenia, and bipolar disorders (Dowlati et al, 2010; Miller et al, 2011; Munkholm et al, 2013). Mechanistically, it is known that inflammation can trigger depressive symptoms and is associated with suicidality based on studies involving patients who receive interferon (IFN)-based or interleukin-2 (IL-2) immuno-therapy (Buter et al, 1993; Capuron et al, 2004; Dieperink et al, 2004; Janssen et al, 1994; Renault et al, 1987). It is well established that $\sim 30-45 \%$ of patients receiving IFN treatment develop depressive-like symptoms during the course of therapy, with a proportion of them experiencing these symptoms long after therapy has ceased (Meyers et al, 1991; Miyaoka et al, 1999). Moreover, healthy volunteers who receive injections of lipopolysaccharide (LPS), a bacterial endotoxin, which induces a strong inflammatory response in the periphery as well as in the central nervous system, experience depressive symptoms (Yirmiya et al, 2000). However, questions arise as to whether inflammation contributes to symptoms of suicidality or merely exists as an epiphenomenon in patients who are considered 'primary psychiatric patients'. Moreover, are there individuals in whom inflammation is particularly pronounced and is associated with a specific symptom profile? Several studies indicate that inflammation may be particularly pronounced in patients who experience suicidality (Figure 1; Table 1). An early study found that patients with a history of suicide attempts have increased blood levels of the soluble IL-2 receptors compared with healthy controls (Nassberger and Traskman-Bendz, 1993). This was followed by two post-mortem studies, which independently provided evidence of increased inflammation in the brains of suicide victims. First, Tonelli et al (2008) reported elevated mRNA transcripts of IL-4 and IL-13 in the orbitofrontal cortex of suicide victims. Subsequently, Steiner et al (2008) demonstrated increased microgliosis, indicative of an enhanced inflammation, in suicide victims with a diagnosis of depression and schizophrenia. These initial findings were supported by a study from our group, showing elevated levels of IL-6 in the cerebrospinal fluid (CSF) of recent suicide attempters. In addition, we observed that IL- 6 levels in these patients correlated with the severity of depression as assessed by Montgomery-Asberg Depression Rating Scale (Lindqvist et al, 2009). A previous study had found lower CSF levels of neuroprotective IL-8 levels in suicide attempters compared with healthy controls, confirming dysregulation of the immune system in suicidal patients (Isung et al, 2012). Since then, we found that decreased IL-8 levels were specific 


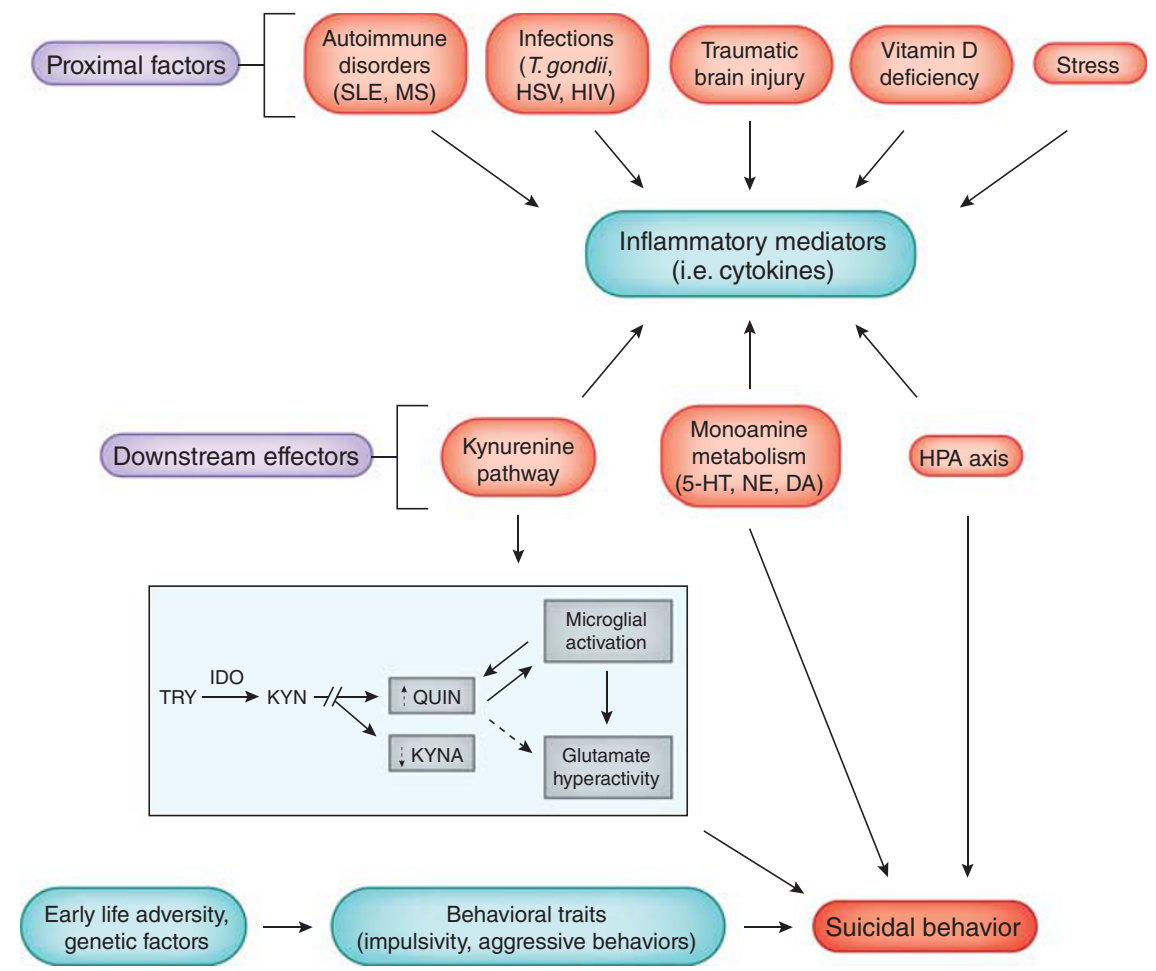

Figure 1. Contributing factors to suicidal behavior etiology. Genetic factors can predispose individuals to behavioral traits that predispose them to exhibit suicidal behavior. Proximal factors with an underlying immune component can induce a sustained immune response, which, then, is known to modulate a variety of downstream effectors including modifying monoamine metabolism, increasing tryptophan metabolism via the kynurenine pathway, and dysregulating the hypothalamic-pituitary axis. KYN, kynurenine; KYNA, kynurenic acid; MS, multiple sclerosis; NE, norepinephrine; QUIN, quinolinic acid; SLE, systemic lupus erythematosus; 5-HT, serotonin.

to patients with anxiety and identified the presence of a single-nucleotide polymorphism in the promoter region of the IL-8 gene, which predicted more severe anxiety in the suicide attempters (Janelidze et al, 2015). Interestingly, O'Donovan et al (2013) demonstrated that increased inflammation correlated with the degree of suicidal ideation in patients with depression, even after controlling for active suicide attempts and degree of depressive symptoms. Limited post-mortem data on teenage suicide victims also points to the association between inflammation and suicide. Pandey et al (2012) reported that post-mortem brain tissue from teenage suicide victims had increased mRNA and protein levels of IL-1 $\beta$, IL-6, and tumor necrosis factor alpha (TNF- $\alpha$ ) in certain cortical regions (Brodmann area 10). More studies are clearly needed to support the relationship between inflammation and suicidality in youth, as suggested by a recent meta-analysis (Kim et al, 2014). Together, these studies suggest that suicidal individuals may have an inflammatory signature irrespective of their primary diagnoses and other underlying conditions. However, there are studies that also report a decrease in cytokine levels in suicidal individuals (Clark et al, 2016; Gabbay et al, 2009). Although some of these discrepancies may be attributed to differences in sample size, study design, and relevant controls, it is critical to acknowledge the complexity of drawing definitive conclusions, while controlling for diverse confounding factors such as medication history, post-mortem tissue integrity, past psychiatric and substance abuse history, and previous suicide attempts. In this context, meta-analyses provide a formal, qualitative assessment of previously published studies, which can then be used to derive conclusions. In one such metaanalysis study that assessed changes in inflammatory cytokines in blood, CSF, and post-mortem tissue of suicidal individuals, Black et al found a robust association between increased suicidality and plasma levels of IL-1 $\beta$ and IL-6. These changes were significant to distinguish psychiatric patients with suicidality from psychiatric patients without suicidality and healthy controls. They also found increased IL- $1 \beta$ and IL- 6 in post-mortem brain tissue from suicide completers and reported that reduced CSF levels of IL-8 were associated with suicidal behavior (Black and Miller, 2015).

In an interesting study, Torres-Platas et al (2014) showed that depressed individuals who committed suicide have a greater proportion of activated microglia in the anterior cingulate cortex white matter compared with subjects without psychiatric disorders who died from other causes. The same group also had specific microglial phenotypes that were associated with concurrent increases in vascular density and increased expression of perivascular macrophage markers. Schnieder et al (2014) reported similar findings, where they observed increased density of perivascular cells in prefrontal cortex white matter of suicide victims. It is known that peripheral cytokines can be trafficked into the CNS either through regions with limited blood-brain barrier (BBB) 
TABLE 1 Clinical Studies Connecting Inflammatory Mediators and Effectors with Suicidal Behavior and Predisposing Behavioral Traits

\begin{tabular}{|c|c|c|c|c|c|}
\hline Study reference & Population & Type of patients & Type of control participants & $\begin{array}{l}\text { Type of biological } \\
\text { sample }\end{array}$ & Study outcomes in patients compared with controls \\
\hline $\begin{array}{l}\text { Nassberger and Traskman- } \\
\text { Bendz, } 1993\end{array}$ & Adults & Suicide attempters & Healthy controls & Plasma & Elevated soluble IL-2 receptors levels \\
\hline Coccaro, 2006 & Adults & $\begin{array}{l}\text { Personality disorder subjects with higher CRP } \\
\text { levels }\end{array}$ & $\begin{array}{l}\text { Personality disorder subjects with } \\
\text { lower CRP levels }\end{array}$ & Plasma & Elevated TNF- $\alpha$ and CRP levels are associated with aggressive traits \\
\hline Steiner et al, 2008 & Adults & $\begin{array}{l}\text { Suicide completers with a diagnosis of } \\
\text { depression and schizophrenia }\end{array}$ & $\begin{array}{l}\text { Non-suicides without psychiatric } \\
\text { disorders }\end{array}$ & Post-mortem brain & Increased microgliosis in cortical and subcortical regions \\
\hline Tonelli et al, 2008 & Adults & Suicide completers & $\begin{array}{l}\text { Non-suicides without psychiatric } \\
\text { disorders }\end{array}$ & Post-mortem brain & $\begin{array}{l}\text { Elevated IL-4 (females) and IL-13 (males) mRNA in orbitofrontal cortical } \\
\text { regions }\end{array}$ \\
\hline Gabbay et al, 2009 & Adolescents & MDD patients with suicidality & Non-suicidal MDD patients & Plasma & Decreased TNF- $\alpha$ levels \\
\hline Lindqvist et al, 2009 & Adults & Suicide attempters & Healthy controls & CSF & Elevated IL-6 levels (correlates with the depression severity) \\
\hline Janelidze et al, 2011 & Adults & Suicide attempters & Non-suicidal depressed patients & Plasma & Elevated levels of IL-6 and TNF- $\alpha$; decreased IL-2 levels \\
\hline Steiner et al, $201 \mathrm{I}$ & Adults & Suicide completers & $\begin{array}{l}\text { Non-suicides without psychiatric } \\
\text { disorders }\end{array}$ & Post-mortem brain & Increased density of QUIN reactive microglia in anterior cingulate cortex \\
\hline Sublette et al, 20I I & Adults & Depressed suicide attempters & Non-suicidal depressed patients & Plasma & Increased kynurenine levels \\
\hline Isung et al, 2012 & Adults & Suicide attempters & Healthy male controls & CSF & Lower IL-8 levels \\
\hline Pandey et al, 2012 & Adolescents & Suicide completers & $\begin{array}{l}\text { Non-suicides without psychiatric } \\
\text { disorders }\end{array}$ & Post-mortem brain & $\begin{array}{l}\text { Increased mRNA and protein levels of IL-I } \beta \text {, IL-6, and TNF- } \alpha \text { in Brodmann } \\
\text { area } 10\end{array}$ \\
\hline Erhardt et al, 2013 & Adults & Suicide attempters & Healthy controls & CSF & $\begin{array}{l}\text { Increased QUIN levels, which positively correlate with IL-6 levels and suicidal } \\
\text { intent; increased QUIN/KYNA ratio }\end{array}$ \\
\hline O'Donovan et al, 2013 & Adults & MDD patients with high suicidal ideation & $\begin{array}{l}\text { MDD patients with low suicidal } \\
\text { ideation }\end{array}$ & Plasma & Elevated IL- 6 and CRP levels but not TNF- $\alpha$ \\
\hline Coccaro et al, 2014 & Adults & $\begin{array}{l}\text { Healthy individuals with intermittent explosive } \\
\text { disorder }\end{array}$ & $\begin{array}{l}\text { Non-aggressive individuals with or } \\
\text { without psychiatric disorders }\end{array}$ & Plasma & $\begin{array}{l}\text { CRP and IL-6 levels are associated with aggressive behaviors compared with } \\
\text { psychiatric or healthy controls }\end{array}$ \\
\hline Isung et al, 2014 & Adults & Suicide attempters & No control group & Plasma and CSF & $\begin{array}{l}\text { Plasma IL-6 levels positively correlate with impulsivity trait and with violent } \\
\text { suicide attempt methods }\end{array}$ \\
\hline Pandey et al, 2014 & Adults & $\begin{array}{l}\text { Depressed and non-depressed suicide } \\
\text { completers }\end{array}$ & $\begin{array}{l}\text { Non-suicidal depressed patients and } \\
\text { healthy controls }\end{array}$ & Post-mortem brain & $\begin{array}{l}\text { Irrespective of psychiatric diagnoses, increased mRNA and protein levels of } \\
\text { TLR3 and TLR4 in dorsolateral prefrontal cortex }\end{array}$ \\
\hline Schnieder et al, 2014 & Adults & Suicide completers & Non-suicides & Post-mortem brain & Activated microglia in ventral prefrontal white matter \\
\hline Torres-Platas et al, 2014 & Adults & Depressed suicide completers & $\begin{array}{l}\text { Non-suicides without psychiatric } \\
\text { disorders }\end{array}$ & Post-mortem brain & $\begin{array}{l}\text { Elevated activated microglia and circulatory macrophages in the dorsal } \\
\text { anterior cingulate white matter }\end{array}$ \\
\hline Bay-Richter et al, 2015 & Adults & Suicide attempters & Healthy controls & CSF & $\begin{array}{l}\text { QUIN levels remain elevated over a period of } 2 \text { years; KYNA levels are } \\
\text { decreased over this time period and correlate with more severe depressive } \\
\text { and suicidal symptoms }\end{array}$ \\
\hline Busse et al, 2015 & Adults & Suicide completers & $\begin{array}{l}\text { Non-suicides without psychiatric } \\
\text { disorders }\end{array}$ & Post-mortem brain & Decreased density of QUIN reactive microglia in hippocampal regions \\
\hline Janelidze et al, 2015 & Adults & Suicide attempters & Healthy controls & Plasma and CSF & $\begin{array}{l}\text { Lower IL-8 levels are specific to patients with anxiety; a SNP in IL-8 gene } \\
\text { promoter predicts more severe anxiety }\end{array}$ \\
\hline Clark et al, 2016 & Adults & $\begin{array}{l}\text { Individuals with depressive disorder who died of } \\
\text { suicide, natural causes, homicide, and accident }\end{array}$ & $\begin{array}{l}\text { Non-suicides without psychiatric } \\
\text { disorders }\end{array}$ & Post-mortem brain & $\begin{array}{l}\text { Lower IFN- } \gamma \text { and TNF- } \alpha \text { levels, decreased KYN/TRY ratio, IDO-I/2, TDO, } \\
\text { and QUIN }\end{array}$ \\
\hline
\end{tabular}

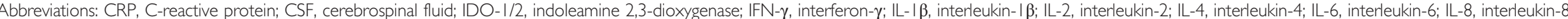

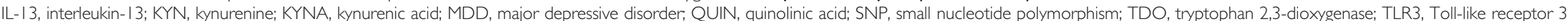

TLR4, Toll-like receptor 4; TNF- $\alpha$, tumor necrosis factor- $\alpha$; TRY, tryptophan. 
permeability, such as the circumventricular organs and the choroid plexus, or through a compromised BBB (Dantzer et al, 2008), which has been reported to be leaky in suicidal individuals (Bayard-Burfield et al, 1996; Falcone et al, 2010; Ventorp et al, 2016). In line with these findings, Wohleb et al demonstrated increased peripheral myeloid cell trafficking into perivascular spaces and specific brain regions using a repeated social defeat stress model. These changes were further accompanied by microglial activation and induction of anxiety-like behavior. This suggests an active role for peripheral myeloid cells in altering neuroimmune response and behavior (Wohleb et al, 2013).

Certain behavioral traits, such as impulsivity and aggression, have been found to confer a greater degree of suicide risk (Brent et al, 1994; McGirr et al, 2008). Clinical studies also indicate a relationship between inflammation and traits of aggression and impulsivity (Coccaro et al, 2014; Isung et al, 2014; Mommersteeg et al, 2008; Suarez et al, 2002). For example, in individuals with personality disorders, elevated TNF- $\alpha$ and C-reactive protein (CRP) are associated with aggressive traits (Coccaro, 2006). Recently, the same group demonstrated that plasma CRP and IL-6 levels are associated with aggressive behavior in individuals diagnosed with intermittent explosive disorders (Coccaro et al, 2014). A study on suicide attempters by Isung et al (2014) found that plasma IL-6 levels were positively correlated with impulsivity trait and with violent suicide attempt methods.

The above-mentioned studies provide evidence that suicidal behavior is associated with the changes in cytokine profiles in peripheral blood as well as in the brain. In addition, it is important to determine whether such changes are specific for suicidal behavior, independent of underlying psychiatric diagnosis. It is also of interest to assess whether similar or different degrees of inflammatory changes are found among individuals with suicidal ideation as well as among suicide attempters and completers. Addressing this, Janelidze et al (2011) observed plasma IL-6 and TNF- $\alpha$ levels to be elevated in suicidal depressed individuals compared with non-suicidal depressed individuals and healthy controls, suggesting that suicidal individuals may have a unique cytokine profile among depressive patients. Supporting this, O'Donovan et al (2013) found that a higher degree of suicidal ideation was associated with an increased inflammatory index in patients independent of the degree of depressive symptoms. These findings are in line with an early hallmark study, showing increased microglial density in schizophrenic and depressed suicide completers, although not in patients from the same diagnostic groups that died from other causes, stressing that the inflammatory changes might be specific to suicidality across diagnostic boundaries (Steiner et al, 2008).

\section{NEUROIMMUNOLOGICAL MECHANISMS INVOLVED IN SUICIDAL BEHAVIOR}

Inflammatory cytokines can be synthesized in the central nervous system or enter the brain from the periphery via different mechanisms, including compromised BBB. We have previously shown that suicide attempters have an increased BBB permeability, which is associated with increased CSF levels of glycosaminoglycan hyaluronic acid, which is a ligand for CD44 and is indicative of increased neuroinflammation (Ventorp et al, 2016).

One of the mechanisms, which could be responsible for the observed increase in inflammatory cytokine levels, is activation of the Toll-like receptors (TLRs). TLRs have a critical role in regulating innate immune response and facilitating immune function in the event of infection (Hanke and Kielian, 2011). They are widely expressed in different cell types of the CNS and are identified to have diverse functions, from cognition to memory (Okun et al, 2010; Okun et al, 2011). In the only study to date on suicidal subjects, Pandey et al (2014), concluded that, irrespective of psychiatric diagnoses, mRNA and protein levels of TLR3 and TLR4 were consistently dysregulated in suicide victims (depressed and non-depressed). Although preliminary, this study, for the first time, demonstrated the role of TLRs in suicide.

Inflammatory cytokines may promote suicidal behavior by several mechanisms. Additional mechanisms by which cytokines may contribute to the pathophysiology of suicidal behavior include activation of the kynurenine pathway of tryptophan catabolism, dysregulation of the HPA axis and alterations in monoamine metabolism, as described below.

The kynurenine pathway consists of a series of enzymes involved in the metabolism of the essential amino acid, tryptophan. The pathway is active in the periphery as well as in the central nervous system. The initial step in metabolism of tryptophan into kynurenine is catalyzed by indoleamine 2,3-dioxygenase (IDO) or tryptophan 2,3-dioxygenase (TDO). Kynurenine is further broken down into highly neuroactive compounds such as quinolinic acid (QUIN) and kynurenic acid (KYNA). Inflammatory cytokines such as IFN- $\gamma$, IL-6, IL- $1 \beta$, and TNF- $\alpha$ are potent activators of IDO and/or TDO (Kim et al, 2012; Mandi and Vecsei, 2012; Schwieler et al, 2015; Taylor and Feng, 1991; Urata et al, 2014). QUIN is one of the neuroactive metabolite that is synthesized in microglia. QUIN is a selective $N$-methyl-Daspartic acid (NMDA) receptor agonist and acts via activation of the NR1+NR2A and NR1+NR2B NMDA receptor subunits (de Carvalho et al, 1996). In addition to NMDA receptor activation, QUIN also inhibits astrocytic uptake of glutamate by inhibiting glutamine synthetase and increases neuronal glutamate release (Tavares et al, 2002). KYNA, on the other hand, blocks the cholinergic $\alpha 7$ nicotinic receptor and antagonizes the glycine site of the NMDA receptor (Hilmas et al, 2001; Stone, 1993). KYNA also antagonizes $\alpha$-amino-3-hydroxy-5-methyl-4-isoxazolepropionic acid (AMPA) receptor, which has been implicated in the pathophysiology of depression and in the mechanism of action of several antidepressant drugs (Freudenberg et al, 2015; Schwarcz et al, 2012). We found QUIN levels in CSF of suicide attempters to be two to three times higher than in healthy controls with no change in KYNA levels. Interestingly, in the same study, QUIN levels positively correlated 
with IL-6 in CSF, indicating that the activation of the kynurenine pathway in these patients was associated with an active inflammatory state. The increase in QUIN was also correlated with the suicidal intent in this cohort of patients (Erhardt et al, 2013). Furthermore, to determine whether QUIN levels remain elevated over time, we measured CSF QUIN for two continuous years after an initial suicide attempt. Not only did we find QUIN to be elevated over 2 years, we also observed that high levels of IL-6 and lower KYNA in the same patient group correlated with the severity of suicidal ideation and depressive symptoms (Bay-Richter et al, 2015). Interestingly, a post-mortem study found increased QUIN immunoreactivity in suicidal depressed patients seemingly in agreement with our findings (Steiner et al, 2011). In the same study, certain regions of the anterior cingulate cortex in suicide victims reportedly contained higher density of QUIN-positive microglia. However, a follow-up study found a decrease in the number of QUIN reactive microglia in the hippocampi from the same suicide victims (Busse et al, 2015). These findings suggest that certain brain regions may be more sensitive to inflammatory insult, which might have contributed to specific differences in the localization of QUIN reactive microglia in the brains of suicide victims. On the other hand, plasma KYNA has been previously shown to be reduced in depressed patients, although neither QUIN nor cytokine levels were profiled in these patients (Myint et al, 2007). Interestingly, we found a twofold increase in CSF QUIN/KYNA ratio in suicide attempters compared with healthy controls. KYNA, being an NMDA receptor antagonist, may induce a net positive effect on NMDA receptor signaling leading to aberrant glutamate signaling (Erhardt et al, 2013).

Evidence suggests that the dysregulation of the kynurenine pathway might be more pronounced in depressed individuals with suicidality than depressed patients without suicidal behavior. Sublette et al (2011) were the first to demonstrate that blood kynurenine levels are elevated in suicide attempters compared with a depressed-only control group. Interestingly, Dahl et al (2015) also reported that depressive episodes in MDD patients are not associated with an increase in plasma kynurenine metabolite levels, despite the presence of elevated cytokine levels in these individuals. In addition, it should be noted that certain metabolites do not freely cross the BBB, and it might, therefore, be of importance to study the CSF levels of metabolites when determining their correlation to neuropsychiatric symptoms (Schwarcz et al, 2012).

So far, only a few studies have compared suicidal depressed individuals with non-suicidal depressive individuals, trying to assess whether the biological changes of these two groups are different or, perhaps, similar but differing in magnitude. Indeed, a multitude of papers have shown that patients with depression display inflammation (Dowlati et al, 2010; Howren et al, 2009; Liu et al, 2012; Valkanova et al, 2013) and the exact same mechanisms (inflammation and activation of the kynurenine pathway) are proposed as the mechanism of depression (particularly of inflammationinduced depression) (Dantzer and Walker, 2014; Maes et al,
2011; Myint et al, 2012; Reus et al, 2015). Evidence at this point is scarce, but indicates that the inflammatory changes and generation of kynurenine neurotoxic metabolites are, at least, more pronounced in suicidal individuals (Janelidze et al, 2011; O'Donovan et al, 2013; Sublette et al, 2011). It is difficult to determine from the available studies whether these changes are actually unique to patients with suicidal ideation or behavior. The reason is that studies on depressive patients frequently do not attempt to distinguish between suicidal and non-suicidal patients. Patients with a certain degree of suicidal ideation are often included among the non-suicidal depressive individuals. Additional studies on this topic are highly warranted in the future.

In addition to the kynurenine pathway activation, inflammatory cytokines can also induce the changes in monoamine metabolism as well as in the HPA axis (Oquendo et al, 2014). Cytokine administration in both animals and humans is known to activate the HPA axis (Dunn, 2000). IFN- $\alpha$ used in the treatment of hepatitis $C$ is a potent activator of the HPA axis as it causes increases in cortisol and adrenocorticotropic hormone levels within several hours of the treatment. HPA axis activation also correlates with the onset of depressive symptoms in patients who undergo interferon therapy compared with those who do not (Capuron et al, 2003). The serotonin system is one of the most widely studied neurotransmitter systems in depressive disorders (Vaswani et al, 2003) and its dysregulation by inflammatory cytokines could be one of the mechanisms underlying suicidal ideation and behavior (Oquendo et al, 2014). IL-1 $\beta$ and TNF- $\alpha$ have been shown to enhance the expression and activation of serotonin transporters in cell lines via a p38 mitogen-activated protein kinase pathway (Mossner et al, 1998; Ramamoorthy et al, 1995; Zhu et al, 2006; Zhu et al, 2005). Acute IL-6 administration is also known to increase serotonin release in rat striatum (Zhang et al, 2001). Alterations in cytokineinduced serotonin metabolism have also been reported. 5-hydroxyl indole acetic acid (5-HIAA), a metabolic product of serotonin, has been shown to be elevated following LPS injections in rodent models of depression (O'Connor et al, 2009). Thus, inflammatory cytokines can influence a variety of neurotransmitter functions, ranging from synthesis to inducing changes directly at the receptor level.

\section{UPSTREAM TRIGGERS OF SUICIDALITY}

The rates of suicidal behavior in individuals affected by conditions that involve the immune system are generally higher than in individuals with somatic conditions that do not increase inflammation. For example, $\sim 1 \%$ of adolescents with hemophilia, a genetic condition that does not involve inflammation, have previously attempted suicide compared with $7 \%$ of adolescents with thalassemia major, a condition that is often characterized by the presence of chronic vascular inflammatory state (Ghanizadeh and BalighJahromi, 2009; Ghanizadeh et al, 2006). Furthermore, causal 
effects of inflammation contributing to depression and suicidal behavior are highlighted by studies showing increased incidence following IFN-based treatment in cancer and hepatitis patients (Capuron et al, 2000; Capuron et al, 2004; Dieperink et al, 2004; Janssen et al, 1994; Miyaoka et al, 1999). It is also known that MDD is more prevalent in patients afflicted with conditions characterized by chronic inflammation (such as cardiovascular diseases, type 2 diabetes, and rheumatoid arthritis) than in the general population (Steptoe, 2007).

\section{AUTOIMMUNE DISORDERS}

Multiple sclerosis (MS) is a chronic inflammatory neurological disorder characterized by sensory and motor loss, cognitive impairment, blindness, and fatigue. Patients with MS report high rates of depression reaching $\sim 40 \%$ in these patients (Chwastiak et al, 2002). In a subset of MS patients with no history of psychiatric illness, treatment with IFN- $\gamma$ worsens depressive symptoms and induces suicidal ideation or attempts (Benros et al, 2011; Chwastiak et al, 2002; Fragoso et al, 2010). Death by suicide may account for at least $15 \%$ of mortality in MS populations (Sadovnick et al, 1991). Another study determined an increased risk for suicide completion in a Swedish cohort of MS patients (Fredrikson et al, 2003). A similar study in a smaller cohort of Danish MS patients identified a twofold increase in risk of death by suicide compared with the general population, with the greatest risk in the first year following diagnosis (Bronnum-Hansen et al, 2005). Systemic lupus erythematosus (SLE) is another autoimmune disorder predominantly affecting women of reproductive age. About $17-71 \%$ of SLE patients present with psychiatric symptoms (Wekking, 1993). Prevalence of depression is estimated to be fourfold higher in SLE patients compared with non-SLE patients with at least $75 \%$ of SLE patients being diagnosed with depression during their lifetime (Palagini et al, 2013). Interestingly, the presence of anti-NR1 antibodies has been consistently reported in the CSF of SLE patients and correlates positively with their neuropsychiatric symptoms (Arinuma et al, 2008; Fragoso-Loyo et al, 2008; Gono et al, 2011; Lapteva et al, 2006; Yoshio et al, 2006). As mentioned above, NR1 is a subunit of the ionotropic glutamate NMDA receptor (PerezOtano et al, 2001). Examining a Chinese population of SLE patients, Pan et al reported a $34 \%$ prevalence of suicidal ideation, with lower estimates ranging from 8 to $12 \%$ reported in other SLE populations across the world (Ishikura et al, 2001; Xie et al, 2012; Zakeri et al, 2012). It is unclear if suicidal thoughts in these patients manifest as a consequence of the disease or from an underlying psychiatric condition or both.

\section{INFECTIONS}

Infections induce inflammation, and, as such, may activate the above-mentioned neuroinflammatory mechanisms leading to depression and suicidal symptoms. Certain infections may be particularly strong triggers of neuroinflammation, as they invade the central nervous system, and such neurotrophic pathogens include herpes viruses, human HIV, and possibly hepatitis $C$ virus. The prevalence of MDD, suicidal ideation, and attempted suicides in HIV patients is reported to be up to $27.2 \%, 31 \%$, and $32.7 \%$, respectively (Serafini et al, 2015). Chronic hepatitis C patients also display a higher prevalence of depression and suicide risk compared with the general population (Lucaciu and Dumitrascu, 2015). Alavi et al (2012) found that, before treatment, $36 \%$ of chronic hepatitis C patients suffer from major depression and 18\% endure a moderate-to-severe suicide risk. A study by Okusaga et al (2011) found higher seropositivity for influenza B virus in patients with a history of suicide attempt, whereas seropositivity for all three types of viruses (influenza A, B, and coronaviruses) was associated with the history of mood disorders. Recently, the onset of de novo depression has been associated with the higher levels of cytomegalovirus IgG antibodies with the odds of incident depression being three times greater in individuals with antibody levels in the highest quartile (Simanek et al, 2014). Certain neurotrophic pathogens are not only capable of inducing inflammation but might manipulate the host neurons in very specific ways to trigger a behavioral response. Toxoplasma gondii is a common protozoan parasite that establishes latency in the muscle and brain (Henriquez et al, 2009). Infection in humans is frequently asymptomatic and can occur, for example, after consumption of undercooked meat infected with parasitic oocysts. The host immune response $\mathrm{CD}^{+}$and $\mathrm{CD}^{+} \mathrm{T}$ cells are responsible for keeping the parasite under control and relatively quiescent in the central nervous system (Gazzinelli et al, 1992). Interestingly, latent $T$. gondii infection has been identified as a risk factor for suicide and suicide attempts (Arling et al, 2009; Ling et al, 2011). Reactivation of infection has also been associated with traits such as aggression and impulsivity, two behavioral endophenotypes associated with suicidal behavior (Cook et al, 2015).

Proposed mechanisms underlying $T$. gondii-associated behavioral changes include alterations in immune response as well as dysfunction associated with dopaminergic neurotransmission. In rodents, for example, infection with T. gondii elicits release of IFN- $\gamma$, IL-12, IL- 8 , and TNF- $\alpha$ primarily by cells of the innate immune system (Miller et al, 2009). Recently, using a rodent model of T. gondii infection, Notarangelo et al (2014) showed that brain kynurenine and QUIN levels are persistently elevated in infected animals. Moreover, the T. gondii genome encodes for tyrosine hydroxylase, a rate-limiting enzyme in the synthesis of dopamine, wherein it catalyzes the conversion of tyrosine into L-DOPA (Gaskell et al, 2009). Using T. Gondii-infected mice, Prandovsky et al showed that increased dopamine staining was restricted to tissue cysts containing the parasite. They also observed increased dopamine release in response to T. gondii infection (Prandovszky et al, 2011). Together, the biological effects of $T$. gondii might include increases in 
the levels of pro-inflammatory cytokines, QUIN, and dopamine, thus altering both glutamatergic and dopaminergic neurotransmission.

\section{TRAUMATIC BRAIN INJURY}

Traumatic brain injury (TBI) results from sudden trauma to the brain. Immune system activation following TBI usually occurs as a secondary event and further worsens existing neuro-degeneration and other neurological impairments following initial trauma. The neuroinflammation is characterized by microglial activation and release of inflammatory factors such as IL- $1 \beta$, TNF- $\alpha$, and IFN- $\gamma$ (Block and Hong, 2005). In a study involving the largest cohort of TBI patients (two million controls and 200000 Swedish TBI patients), it was determined that those with TBI are three times more likely to die of suicide than controls (Fazel et al, 2014). To determine whether increases in inflammatory mediators are associated with TBI, Jeungst and colleagues measured TNF- $\alpha$ levels in serum and CSF of TBI patients 6 and 12 months following initial injury. Not only did elevated TNF- $\alpha$ levels correlate with TBI but they also found positive correlations between TNF- $\alpha$ levels and disinhibition (a behavioral proxy for impulsivity), as well as disinhibition and suicidal ideation at various time points. Thus, they found an alternative rational for the etiology of TBI, involving immune activation and increase in cognitive deficits associated with impulse control and suicidal behavior (Juengst et al, 2014). A study by Mackay et al (2006) found an increase in activation of the kynurenine pathway, which was sustained for at least 1 year (and possibly longer) following TBI. Meanwhile, another study determined that during the first year after mild-to-severe TBI, suicidal ideation was present in $25 \%$ of patients (Mackelprang et al, 2014). These long-lasting effects of the TBI could be, in part, responsible for the increased risk of suicidality observed in veterans (Brenner et al, 2011).

\section{VITAMIN D DEFICIENCY}

Low levels of vitamin D have been linked with MDD and other psychiatric illnesses (Kjaergaard et al, 2011), and recent studies have begun to explore its role in suicidal behavior. Umhau et al (2013) investigated vitamin D status in a cohort of active duty military service professional and found that low levels of vitamin D correlate with increased suicide risk. Although it is still unclear how vitamin $\mathrm{D}$ is associated with suicidal behavior, it is plausible that its immune-modulatory functions might have a role. 1,25-dihydroxyvitamin D3 attenuates immune response by suppressing the effects of IL-2 and IFN- $\gamma$, produced by Th1 cells, subsequently preventing the activation and proliferation of T-cell populations (Cippitelli and Santoni, 1998). Furthermore, vitamin D also inhibits the release of cytokines such as IL- 6 and TNF- $\alpha$ from human monocytes (Zhang et al, 2012). Grudet et al compared vitamin D levels in suicide attempters, non-suicidal depressed patients, and healthy individuals, and found that suicidal patients had significantly lower levels of vitamin $\mathrm{D}$, compared with the other groups, and that $58 \%$ of the suicide attempters were severely vitamin $\mathrm{D}$ deficient. Lower vitamin $\mathrm{D}$ levels also correlated with elevated levels of inflammatory cytokines in the suicidal and depressive patients (Grudet et al, 2014).

\section{THERAPY}

Several clinical trials have found that ketamine robustly decreases depressive and suicidal symptoms in as little as 40 min with effects lasting for several weeks (DiazGranados et al, 2010; Larkin and Beautrais, 2011; Price and Mathew, 2015; Price et al, 2009; Zarate et al, 2012). Animal studies also showed that ketamine is capable of reducing depressive effects in LPS-injected mice, which exhibit activation of the kynurenine pathway in the brain through IDO induction (O'Connor et al, 2009; Walker et al, 2013). As ketamine is an NMDA receptor antagonist, its observed beneficial effects could be due to its competing action with neurotoxic QUIN, an NMDA receptor agonist. In addition, ketamine can be metabolized in vivo via $\mathrm{P} 450$ enzymes to produce various metabolites, some of which are biologically active, such as $(2 \mathrm{R}, 6 \mathrm{R})$-hydroxynorketamine (HNK), and mediate antidepressant effects by activation of AMPA receptors (Zanos et al, 2016). Currently, there are several ongoing clinical trials investigating whether repeated administration or different doses of ketamine are able to increase its efficacy in various psychiatric disorders (US National Institute of Health, 2016).

Another drug with therapeutic potential to treat MDD and suicidal behavior includes 4-chloro-kynurenine (4-Cl-KYN), which is a brain-penetrating prodrug of 7-chloro-kynurenic acid, and works by blocking the glycine co-agonist site of the NMDA receptor. 4-Cl-KYN exerts similar antidepressant effects of ketamine, but not side effects in animal models (Zanos et al, 2015). Interestingly, these beneficial moodaltering effects are contingent on the activity of AMPA receptors, suggesting an important relationship between NMDA and AMPA receptors in generating antidepressant response. There is, currently, an ongoing clinical trial testing the antidepressant effects of 4-Cl-KYN in MDD patients (US National Institute of Health, 2016).

Another potentially promising pharmacological target is glycogen synthase kinase-3 (GSK3), which raises the levels of pro-inflammatory cytokines and, thus, is thought to promote the development of aggression and depressive symptoms, which are closely linked to development of suicidality (Beurel and Jope, 2014). Administration of lithium, which exhibits anti-inflammatory effects through inhibition of GSK3, has been found effective in decreasing depressive-like and aggressive behavior in animal models (Beurel and Jope, 2014) and reducing suicidal attempts and suicide completion in patients with bipolar as well as unipolar depression (Baldessarini et al, 2006; Guzzetta et al, 2007).

Other potential drug targets include cyclooxygenase-2 (COX-2) inhibitors, which are selective nonsteroidal 
anti-inflammatory drugs. Several recent meta-analyses of randomized controlled trials (RCTs) have found a COX-2 inhibitor celecoxib to be an effective add-on treatment for unipolar depression as celecoxib decreases depression severity and increases remission rates (Faridhosseini et al, 2014; Na et al, 2014). A RCT conducted by Nery et al (2008) has found that adjunctive treatment with celecoxib is able to produce a rapid antidepressant effect in bipolar disorder patients during depressive or mixed phases.

Infliximab, which is a monoclonal antibody against TNF- $\alpha$, has also shown some antidepressant effects, as it is able to decrease depressive symptoms in patients with treatment-resistant depression and elevated levels of plasma inflammatory biomarkers (Raison et al, 2013). A new, recently started RCT will evaluate the effect of adjunctively administrated infliximab on bipolar I and II depression (US National Institute of Health, 2016). Other clinical studies have shown that infliximab and etanercept, another TNF- $\alpha$ blocker, are capable of improving symptoms of depression in patients with various inflammatory conditions (ErsozluBozkirli et al, 2015; Ertenli et al, 2012; Gelfand et al, 2008; Minderhoud et al, 2007; Tookman et al, 2008).

Minocycline, which is a broad-range tetracycline antibiotic capable of decreasing microglial activation, is another promising treatment for depressive symptoms. Preliminary data from an open-label study of patients with MDD suggest that adjunctive minocycline treatment is able to reduce the severity of depressive and psychotic symptoms (Miyaoka et al, 2012). Currently, ongoing RCTs are investigating the effect of minocycline add-on treatment for the management of depressive symptoms in patients with treatment-resistant depression (Husain et al, 2015), MDD (Dean et al, 2014), and bipolar depression (Savitz et al, 2012).

Other anti-inflammatory drugs with therapeutic promise in the treatment of depressive and suicidal symptoms include those targeting cytokine IL- 6 and its biological function. An example of such drug is tocilizumab, a monoclonal anti-IL-6 receptor antibody that works by preventing the IL-6 ligand from binding to the IL-6 receptors. Previous studies have found that tocilizumab is able to effectively treat several inflammatory and autoimmune diseases (Choy et al, 2002; Fonseka et al, 2015; Ito et al, 2004) and a recently initiated RCT will access the ability of tocilizumab to decrease depressive symptomology in treatment-resistant depression (US National Institute of Health, 2016). A more recently developed drug is the human anti-IL-6 monoclonal antibody-sirukumab. In previous studies, sirukumab was able to decrease inflammatory symptoms in patients with rheumatoid arthritis (Smolen et al, 2014; Tanaka and Martin Mola, 2014). An ongoing RCT will assess the efficacy and safety of an add-on sirukumab treatment in MDD patients (US National Institute of Health, 2016).

Pentoxifylline is a phosphodiesterase inhibitor, which, among other effects, decreases the expression of proinflammatory cytokines such as TNF- $\alpha$, IL-1, and IL-6 in blood cells (Ferrari et al, 2010; Gonzalez-Espinoza et al, 2012; Neuner et al, 1994; Pollice et al, 2001). Although it has also been shown to decrease depressive-like behavior in animal models (Bah et al, 2011; Elgarf et al, 2014), whether it can be replicated in humans has not yet been determined. A recently started RCT will attempt to shed some light, as it will explore whether pentoxifylline is able to reduce depressive symptoms, as well as improve artery function, in older primary care patients (US National Institute of Health, 2016).

Most of the above-mentioned anti-inflammatory treatments are in the process of being tested for their effectiveness as anti-depressive action. As discussed in the above sections of this review, irrespective of psychiatric condition, suicidal patients and those at increased suicidal risk often display pronounced inflammatory changes and, therefore, might benefit from anti-inflammatory therapies. Unfortunately, suicidal patients are frequently excluded from the initial phase of investigation due to the safety concerns. Thus, whether the mentioned anti-inflammatory treatments could be additionally used as effective therapies for suicidal behavior remains to be studied in well-designed clinical trials.

\section{CONCLUSIONS}

Mounting evidence implicates dysregulation of the immune system in pathophysiology of suicidality. The potential upstream triggers of suicidal behavior include various inflammatory conditions (TBI, vitamin deficiency, autoimmune disorders, and infections), which, through raised levels of inflammatory mediators, can cause dysregulation of the kynurenine pathway of tryptophan catabolism, hyperactivation of the HPA axis, and alterations in monoamine metabolism in the patients. These neurobiological effects might cause profound changes in emotion and behavior, which could ultimately lead to suicide in vulnerable individuals. More studies are needed to further characterize the interconnection between upstream triggers of inflammation, downstream mediators, and predisposition factors, which, in the presence of inflammation, confer resilience or vulnerability towards development of suicidality.

Currently, anti-inflammatory treatments, initially approved for other conditions, are being tested in depressive individuals. Although for safety concerns, actively suicidal individuals and those at increased suicide risk are excluded from such clinical trials, it may be of key importance to include suicidal individuals in the future as this patient group exhibits the most pronounced inflammatory changes, likely to respond to treatment. Ketamine, an NMDA receptor antagonist, which might counteract some of the actions of the kynurenine pathway metabolites, is being specifically tested in suicidal individuals.

In the future, it may prove to be advantageous to target additional signaling and regulatory mechanisms involved in neuroinflammation. Such targets could include TLRs, activation of which regulates the production of proinflammatory cytokines, as some studies have found some abnormalities in brain and blood TLRs' levels in depressed 
and suicidal patients (Pandey et al, 2014; Wu et al, 2015). Another target could be regulation of the balance between Th1 and Th2-type T-cell populations, as several studies have found an imbalance of these cell types and their corresponding cytokines in the blood of MDD patients with suicidality (Huang and Lee, 2007; Kim et al, 2008; Mendlovic et al, 1999).

Altogether, as neuroinflammation is gradually becoming more accepted as a cause of behavioral symptoms in suicidal individuals, a wide range of novel treatment options, targeting either upstream or downstream factors in the inflammatory cascade, are showing promise to help affected patients. As such, the future for development of novel therapies in psychiatry looks brighter than in decades.

\section{FUNDING AND DISCLOSURE}

LB was supported by the National Institute of Mental Health (NIMH) (MH104622) and Van Andel Research Institute internal grants. The remaining authors declare no conflict of interest.

\section{ACKNOWLEDGMENTS}

We thank Jamie Grit for critical reading of the manuscript and her help with the figure.

\section{REFERENCES}

Alavi M, Grebely J, Matthews GV, Petoumenos K, Yeung B, Day C et al (2012). Effect of pegylated interferon-alpha-2a treatment on mental health during recent hepatitis C virus infection. J Gastroenterol Hepatol 27: 957-965.

Arinuma Y, Yanagida T, Hirohata S (2008). Association of cerebrospinal fluid antiNR2 glutamate receptor antibodies with diffuse neuropsychiatric systemic lupus erythematosus. Arthritis Rheum 58: 1130-1135.

Arling TA, Yolken RH, Lapidus M, Langenberg P, Dickerson FB, Zimmerman SA et al (2009). Toxoplasma gondii antibody titers and history of suicide attempts in patients with recurrent mood disorders. J Nerv Ment Dis 197: 905-908.

Arsenault-Lapierre G, Kim C, Turecki G (2004). Psychiatric diagnoses in 3275 suicides: a meta-analysis. BMC Psychiatry 4: 37.

Bah TM, Kaloustian S, Rousseau G, Godbout R (2011). Pretreatment with pentoxifylline has antidepressant-like effects in a rat model of acute myocardial infarction. Behav Pharmacol 22: 779-784.

Baldessarini RJ, Tondo L, Davis P, Pompili M, Goodwin FK, Hennen J (2006). Decreased risk of suicides and attempts during long-term lithium treatment: a meta-analytic review. Bipolar Disord 8: 625-639.

Bayard-Burfield L, Alling C, Blennow K, Jonsson S, Traskman-Bendz L (1996). Impairment of the blood-CSF barrier in suicide attempters. Eur Neuropsychopharmacol 6: 195-199.

Bay-Richter C, Linderholm KR, Lim CK, Samuelsson M, Traskman-Bendz L, Guillemin GJ et al (2015). A role for inflammatory metabolites as modulators of the glutamate $\mathrm{N}$-methyl-D-aspartate receptor in depression and suicidality. Brain Behav Immun 43: 110-117.

Benros ME, Nielsen PR, Nordentoft M, Eaton WW, Dalton SO, Mortensen PB (2011). Autoimmune diseases and severe infections as risk factors for schizophrenia: a 30-year population-based register study. Am J Psychiatry 168: 1303-1310.

Bertolote JM, Fleischmann A, De Leo D, Phillips MR, Botega NJ, Vijayakumar L et al (2010). Repetition of suicide attempts: data from emergency care settings in five culturally different low- and middle-income countries participating in the WHO SUPRE-MISS Study. Crisis 31: 194-201.

Beurel E, Jope RS (2014). Inflammation and lithium: clues to mechanisms contributing to suicide-linked traits. Trans/ Psychiatry 4: e488.

Black C, Miller BJ (2015). Meta-analysis of cytokines and chemokines in suicidality: distinguishing suicidal versus nonsuicidal patients. Biol Psychiatry 78: 28-37.
Block ML, Hong JS (2005). Microglia and inflammation-mediated neurodegeneration: multiple triggers with a common mechanism. Prog Neurobiol 76: 77-98.

Brenner LA, Ignacio RV, Blow FC (2011). Suicide and traumatic brain injury among individuals seeking Veterans Health Administration services. I Head Trauma Rehabil 26: 257-264.

Brent DA, Johnson BA, Perper J, Connolly J, Bridge J, Bartle S et al (1994). Personality disorder, personality traits, impulsive violence, and completed suicide in adolescents. J Am Acad Child Adolesc Psychiatry 33: 1080-1086.

Brent DA, Bridge J, Johnson BA, Connolly J (1996). Suicidal behavior runs in families. A controlled family study of adolescent suicide victims. Arch Gen Psychiatry 53: 1145-1152.

Brezo J, Paris J, Vitaro F, Hebert M, Tremblay RE, Turecki G (2008). Predicting suicide attempts in young adults with histories of childhood abuse. Br J Psychiatry 193: 134-139.

Bronnum-Hansen H, Stenager E, Nylev Stenager E, Koch-Henriksen N (2005). Suicide among Danes with multiple sclerosis. J Neurol Neurosurg Psychiatry 76: 1457-1459.

Busse M, Busse S, Myint AM, Gos T, Dobrowolny H, Muller UJ et al (2015). Decreased quinolinic acid in the hippocampus of depressive patients: evidence for local anti-inflammatory and neuroprotective responses? Eur Arch Psychiatry Clin Neurosci 265: 321-329.

Buter J, de Vries EG, Sleiffer DT, Willemse PH, Mulder NH (1993). Neuropsychiatric symptoms during treatment with interleukin-2. Lancet 341: 628.

Canetto SS, Sakinofsky I (1998). The gender paradox in suicide. Suicide Life Threat Behav 28: 1-23.

Capuron L, Ravaud A, Dantzer R (2000). Early depressive symptoms in cancer patients receiving interleukin 2 and/or interferon alfa-2b therapy. J Clin Oncol 18: 2143-2151.

Capuron L, Raison CL, Musselman DL, Lawson DH, Nemeroff CB, Miller AH (2003). Association of exaggerated HPA axis response to the initial injection of interferonalpha with development of depression during interferon-alpha therapy. Am J Psychiatry 160: 1342-1345.

Capuron L, Ravaud A, Miller AH, Dantzer R (2004). Baseline mood and psychosocial characteristics of patients developing depressive symptoms during interleukin-2 and/or interferon-alpha cancer therapy. Brain Behav Immun 18: 205-213.

Choy EH, Isenberg DA, Garrood T, Farrow S, loannou Y, Bird H et al (2002). Therapeutic benefit of blocking interleukin- 6 activity with an anti-interleukin-6 receptor monoclonal antibody in rheumatoid arthritis: a randomized, double-blind, placebo-controlled, dose-escalation trial. Arthritis Rheum 46: 3143-3150.

Chwastiak L, Ehde DM, Gibbons LE, Sullivan M, Bowen JD, Kraft GH (2002). Depressive symptoms and severity of illness in multiple sclerosis: epidemiologic study of a large community sample. Am J Psychiatry 159: 1862-1868.

Cippitelli M, Santoni A (1998). Vitamin D3: a transcriptional modulator of the interferon-gamma gene. Eur J Immunol 28: 3017-3030.

Clark SM, Pocivavsek A, Nicholson JD, Notarangelo FM, Langenberg P, McMahon RP et al (2016). Reduced kynurenine pathway metabolism and cytokine expression in the prefrontal cortex of depressed individuals. J Psychiatry Neurosci 41: 150226.

Coccaro EF (2006). Association of C-reactive protein elevation with trait aggression and hostility in personality disordered subjects: a pilot study. J Psychiatr Res 40: 460-465.

Coccaro EF, Lee R, Coussons-Read M (2014). Elevated plasma inflammatory markers in individuals with intermittent explosive disorder and correlation with aggression in humans. JAMA Psychiatry 71: 158-165.

Cook TB, Brenner LA, Cloninger CR, Langenberg P, Igbide A, Giegling I et al (2015). 'Latent' infection with Toxoplasma gondii: association with trait aggression and impulsivity in healthy adults. J Psychiatr Res 60: 87-94.

Crosby AE, Ortega L, Melanson C (2011). Self-directed Violence Surveillance: Uniform Definitions and Recommended Data Elements. Centers for Disease Control \& Prevention, National Center for Injury Prevention and Control: Atlanta, GA, USA.

Cuomo C, Sarchiapone M, Giannantonio MD, Mancini M, Roy A (2008). Aggression, impulsivity, personality traits, and childhood trauma of prisoners with substance abuse and addiction. Am J Drug Alcohol Abuse 34: 339-345.

Da Cruz D, Pearson A, Saini P, Miles C, While D, Swinson N et al (2011). Emergency department contact prior to suicide in mental health patients. Emerg Med $\mathrm{J} \mathbf{2 8}$ : 467-471.

Dahl J, Andreassen OA, Verkerk R, Malt UF, Sandvik L, Brundin L et al (2015). Ongoing episode of major depressive disorder is not associated with elevated plasma levels of kynurenine pathway markers. Psychoneuroendocrinology 56: $12-22$.

Dantzer R, O'Connor JC, Freund GG, Johnson RW, Kelley KW (2008). From inflammation to sickness and depression: when the immune system subjugates the brain. Nat Rev Neurosci 9: 46-56. 
Dantzer R, Walker AK (2014). Is there a role for glutamate-mediated excitotoxicity in inflammation-induced depression? J Neural Transm Nienna) 121: 925-932.

de Carvalho LP, Bochet P, Rossier J (1996). The endogenous agonist quinolinic acid and the non endogenous homoquinolinic acid discriminate between NMDAR2 receptor subunits. Neurochem Int 28: 445-452.

Dean OM, Maes M, Ashton M, Berk L, Kanchanatawan B, Sughondhabirom A et al (2014). Protocol and rationale-the efficacy of minocycline as an adjunctive treatment for major depressive disorder: a double blind, randomised, placebo controlled trial. Clin Psychopharmacol Neurosci 12: 180-188.

DiazGranados N, Ibrahim LA, Brutsche NE, Ameli R, Henter ID, Luckenbaugh DA et al (2010). Rapid resolution of suicidal ideation after a single infusion of an $\mathrm{N}$-methyl-D-aspartate antagonist in patients with treatment-resistant major depressive disorder. J Clin Psychiatry 71: 1605-1611.

Dieperink E, Ho SB, Tetrick L, Thuras P, Dua K, Willenbring ML (2004). Suicidal ideation during interferon-alpha2b and ribavirin treatment of patients with chronic hepatitis C. Gen Hosp Psychiatry 26: 237-240.

Dowlati Y, Herrmann N, Swardfager W, Liu H, Sham L, Reim EK et al (2010). A metaanalysis of cytokines in major depression. Biol Psychiatry 67: 446-457.

Dunn AJ (2000). Cytokine activation of the HPA axis. Ann NY Acad Sci 917: 608-617.

Elgarf AS, Aboul-Fotouh S, Abd-Alkhalek HA, El Tabbal M, Hassan AN, Kassim SK et al (2014). Lipopolysaccharide repeated challenge followed by chronic mild stress protocol introduces a combined model of depression in rats: reversibility by imipramine and pentoxifylline. Pharmacol Biochem Behav 126: 152-162.

Erhardt S, Lim CK, Linderholm KR, Janelidze S, Lindqvist D, Samuelsson M et al (2013). Connecting inflammation with glutamate agonism in suicidality. Neuropsychopharmacology 38: 743-752.

Ersozlu-Bozkirli ED, Keskek SO, Bozkirli E, Yucel AE (2015). The effect of infliximab on depressive symptoms in patients with ankylosing spondylitis. Acta Reumatol Port 40: 262-267.

Ertenli I, Ozer S, Kiraz S, Apras SB, Akdogan A, Karadag O et al (2012). Infliximab, a TNF-alpha antagonist treatment in patients with ankylosing spondylitis: the impact on depression, anxiety and quality of life level. Rheumatol Int 32: 323-330.

Falcone T, Fazio V, Lee C, Simon B, Franco K, Marchi N et al (2010). Serum S100B: a potential biomarker for suicidality in adolescents? PloS One 5: e11089.

Faridhosseini F, Sadeghi R, Farid L, Pourgholami M (2014). Celecoxib: a new augmentation strategy for depressive mood episodes. A systematic review and meta-analysis of randomized placebo-controlled trials. Human psychopharmacology 29: 216-223.

Fazel S, Wolf A, Pillas D, Lichtenstein P, Langstrom N (2014). Suicide, fatal injuries, and other causes of premature mortality in patients with traumatic brain injury: a 41-year Swedish population study. JAMA Psychiatry 71: 326-333.

Ferrari P, Mallon D, Trinder D, Olynyk JK (2010). Pentoxifylline improves haemoglobin and interleukin-6 levels in chronic kidney disease. Nephrology 15 344-349.

Fonseka TM, Mclntyre RS, Soczynska JK, Kennedy SH (2015). Novel investigational drugs targeting IL-6 signaling for the treatment of depression. Expert Opin Investig Drugs 24: 459-475.

Fragoso-Loyo H, Cabiedes J, Orozco-Narvaez A, Davila-Maldonado L, AtishaFregoso Y, Diamond B et al (2008). Serum and cerebrospinal fluid autoantibodies in patients with neuropsychiatric lupus erythematosus. Implications for diagnosis and pathogenesis. PloS One 3: e3347

Fragoso YD, Frota ER, Lopes JS, Noal JS, Giacomo MC, Gomes S et al (2010). Severe depression, suicide attempts, and ideation during the use of interferon beta by patients with multiple sclerosis. Clin Neuropharmaco/ 33: 312-316.

Fredrikson S, Cheng Q, Jiang GX, Wasserman D (2003). Elevated suicide risk among patients with multiple sclerosis in Sweden. Neuroepidemiology 22: 146-152.

Freudenberg F, Celikel T, Reif A (2015). The role of alpha-amino-3-hydroxy-5methyl-4-isoxazolepropionic acid (AMPA) receptors in depression: central mediators of pathophysiology and antidepressant activity? Neurosci Biobehav Rev 52: 193-206.

Gabbay V, Klein RG, Guttman LE, Babb JS, Alonso CM, Nishawala M et al (2009). A preliminary study of cytokines in suicidal and nonsuicidal adolescents with major depression. J Child Adolesc Psychopharmacol 19: 423-430.

Gaskell EA, Smith JE, Pinney JW, Westhead DR, McConkey GA (2009). A unique dual activity amino acid hydroxylase in Toxoplasma gondii. PloS One 4: e4801.

Gazzinelli R, Xu YH, Hieny S, Cheever A, Sher A (1992). Simultaneous depletion of $\mathrm{Cd} 4+$ and $\mathrm{Cd} 8+$ lymphocytes-T is required to reactivate chronic infection with Toxoplasma gondii. J Immunol 149: 175-180

Gelfand JM, Kimball AB, Mostow EN, Chiou CF, Patel V, Xia HA et al (2008). Patientreported outcomes and health-care resource utilization in patients with psoriasis treated with etanercept: continuous versus interrupted treatment. Value Health 11: 400-407.
Ghanizadeh A, Baligh-Jahromi P (2009). Depression, anxiety and suicidal behaviour in children and adolescents with Haemophilia. Haemophilia 15: 528-532.

Ghanizadeh A, Khajavian S, Ashkani H (2006). Prevalence of psychiatric disorders, depression, and suicidal behavior in child and adolescent with thalassemia major. J Pediatr Hematol Oncol 28: 781-784.

Gono T, Kawaguchi Y, Kaneko H, Nishimura K, Hanaoka M, Kataoka S et al (2011). Anti-NR2A antibody as a predictor for neuropsychiatric systemic lupus erythematosus. Rheumatology 50: 1578-1585.

Gonzalez-Espinoza L, Rojas-Campos E, Medina-Perez M, Pena-Quintero P, Gomez-Navarro B, Cueto-Manzano AM (2012). Pentoxifylline decreases serum levels of tumor necrosis factor alpha, interleukin 6 and C-reactive protein in hemodialysis patients: results of a randomized double-blind, controlled clinical trial. Nephrol Dial Transplant 27: 2023-2028.

Grudet C, Malm J, Westrin A, Brundin L (2014). Suicidal patients are deficient in vitamin D, associated with a pro-inflammatory status in the blood. Psychoneuroendocrinology 50: 210-219.

Guzzetta F, Tondo L, Centorrino F, Baldessarini RJ (2007). Lithium treatment reduces suicide risk in recurrent major depressive disorder. J Clin Psychiatry 68: 380-383.

Hanke ML, Kielian T (2011). Toll-like receptors in health and disease in the brain: mechanisms and therapeutic potential. Clin Sci 121: 367-387.

Henriquez SA, Brett R, Alexander J, Pratt J, Roberts CW (2009). Neuropsychiatric disease and Toxoplasma gondii infection. Neuroimmunomodulation 16: 122-133.

Hilmas C, Pereira EF, Alkondon M, Rassoulpour A, Schwarcz R, Albuquerque EX (2001). The brain metabolite kynurenic acid inhibits alpha7 nicotinic receptor activity and increases non-alpha7 nicotinic receptor expression: physiopathological implications. J Neurosci 21: 7463-7473.

Howren MB, Lamkin DM, Suls J (2009). Associations of depression with C-reactive protein, IL-1, and IL-6: a meta-analysis. Psychosom Med 71: 171-186.

Huang TL, Lee CT (2007). T-helper 1/T-helper 2 cytokine imbalance and clinical phenotypes of acute-phase major depression. Psychiatry Clin Neurosci 61 415-420.

Husain MI, Chaudhry IB, Rahman RR, Hamirani MM, Qurashi I, Khoso AB et al (2015). Minocycline as an adjunct for treatment-resistant depressive symptoms: study protocol for a pilot randomised controlled trial. Trials 16: 410.

Ishikura R, Morimoto N, Tanaka K, Kinukawa N, Yoshizawa S, Horiuchi T et al (2001). Factors associated with anxiety, depression and suicide ideation in female outpatients with SLE in Japan. Clin Rheumatol 20: 394-400.

Isung J, Aeinehband S, Mobarrez F, Martensson B, Nordstrom P, Asberg M et al (2012). Low vascular endothelial growth factor and interleukin-8 in cerebrospina fluid of suicide attempters. Transl Psychiatry 2: e196.

Isung J, Aeinehband S, Mobarrez F, Nordstrom P, Runeson B, Asberg M et al (2014). High interleukin-6 and impulsivity: determining the role of endophenotypes in attempted suicide. Trans/ Psychiatry 4: e470.

Ito H, Takazoe M, Fukuda Y, Hibi T, Kusugami K, Andoh A et al (2004). A pilot randomized trial of a human anti-interleukin-6 receptor monoclonal antibody in active Crohn's disease. Gastroenterology 126: 989-996.

Janelidze S, Mattei D, Westrin A, Traskman-Bendz L, Brundin L (2011). Cytokine levels in the blood may distinguish suicide attempters from depressed patients. Brain Behav Immun 25: 335-339.

Janelidze S, Suchankova P, Ekman A, Erhardt S, Sellgren C, Samuelsson M et al (2015). Low IL-8 is associated with anxiety in suicidal patients: genetic variation and decreased protein levels. Acta Psychiatr Scand 131: 269-278.

Janssen HL, Brouwer JT, van der Mast RC, Schalm SW (1994). Suicide associated with alfa-interferon therapy for chronic viral hepatitis. J Hepatol 21: 241-243.

Juengst SB, Kumar RG, Arenth PM, Wagner AK (2014). Exploratory associations with tumor necrosis factor-alpha, disinhibition and suicidal endorsement after traumatic brain injury. Brain Behav Immun 41: 134-143.

Kim YK, Lee SW, Kim SH, Shim SH, Han SW, Choi SH et al (2008). Differences in cytokines between non-suicidal patients and suicidal patients in major depression. Prog Neuropsychopharmacol Biol Psychiatry 32: 356-361.

Liu Y, Ho RC, Mak A (2012). Interleukin (IL)-6, tumour necrosis factor alpha (TNF-alpha) and soluble interleukin-2 receptors (sIL-2R) are elevated in patients with major depressive disorder: a meta-analysis and meta-regression. J Affect Disord 139: 230-239.

Kim H, Chen L, Lim G, Sung B, Wang S, McCabe MF et al (2012). Brain indoleamine 2,3-dioxygenase contributes to the comorbidity of pain and depression. J Clin Invest 122: 2940-2954.

Kim JW, Szigethy EM, Melhem NM, Saghafi EM, Brent DA (2014). Inflammatory markers and the pathogenesis of pediatric depression and suicide: a systematic review of the literature. J Clin Psychiatry 75: 1242-1253.

Kjaergaard M, Joakimsen R, Jorde R (2011). Low serum 25-hydroxyvitamin D levels are associated with depression in an adult Norwegian population. Psychiatry Res 190: 221-225. 
Labonte B, Suderman M, Maussion G, Lopez JP, Navarro-Sanchez L, Yerko V et al (2013). Genome-wide methylation changes in the brains of suicide completers. Am J Psychiatry 170: 511-520.

Labonte B, Suderman M, Maussion G, Navaro L, Yerko V, Mahar I et al (2012). Genome-wide epigenetic regulation by early-life trauma. Arch Gen Psychiatry 69: 722-731.

Lapteva L, Nowak M, Yarboro CH, Takada K, Roebuck-Spencer T, Weickert T et al (2006). Anti-N-methyl-D-aspartate receptor antibodies, cognitive dysfunction, and depression in systemic lupus erythematosus. Arthritis Rheum 54: 2505-2514.

Larkin GL, Beautrais AL (2011). A preliminary naturalistic study of low-dose ketamine for depression and suicide ideation in the emergency department. Int $J$ Neuropsychopharmacol 14: 1127-1131.

Lindqvist D, Janelidze S, Hagell P, Erhardt S, Samuelsson M, Minthon L et al (2009). Interleukin-6 is elevated in the cerebrospinal fluid of suicide attempters and related to symptom severity. Biol Psychiatry 66: 287-292.

Ling VJ, Lester D, Mortensen PB, Langenberg PW, Postolache $\Pi$ (2011). Toxoplasma gondii Seropositivity and Suicide Rates in Women. J Nerv Ment Dis 199: 440-444.

Lucaciu LA, Dumitrascu DL (2015). Depression and suicide ideation in chronic hepatitis $C$ patients untreated and treated with interferon: prevalence, prevention, and treatment. Ann Gastroenterol 28: 440-447.

Maes M, Leonard BE, Myint AM, Kubera M, Verkerk R (2011). The new '5-HT' hypothesis of depression: cell-mediated immune activation induces indoleamine 2,3-dioxygenase, which leads to lower plasma tryptophan and an increased synthesis of detrimental tryptophan catabolites (TRYCATs), both of which contribute to the onset of depression. Prog Neuropsychopharmacol Biol Psychiatry 35: 702-721.

Mackay GM, Forrest CM, Stoy N, Christofides J, Egerton M, Stone TW et al (2006). Tryptophan metabolism and oxidative stress in patients with chronic brain injury. Eur J Neurol 13: 30-42.

Mackelprang JL, Bombardier CH, Fann JR, Temkin NR, Barber JK, Dikmen SS (2014). Rates and predictors of suicidal ideation during the first year after traumatic brain injury. Am J Public Health 104: e100-e107.

Mandi Y, Vecsei L (2012). The kynurenine system and immunoregulation. J Neural Transm Vienna) 119: 197-209.

Mann JJ (2003). Neurobiology of suicidal behaviour. Nat Rev Neurosci 4: 819-828.

McGirr A, Renaud J, Bureau A, Seguin M, Lesage A, Turecki G (2008). Impulsiveaggressive behaviours and completed suicide across the life cycle: a predisposition for younger age of suicide. Psychological Med 38: 407-417.

McGowan PO, Sasaki A, D'Alessio AC, Dymov S, Labonte B, Szyf M et al (2009). Epigenetic regulation of the glucocorticoid receptor in human brain associates with childhood abuse. Nat Neurosci 12: 342-348.

Mendlovic S, Mozes E, Eilat E, Doron A, Lereya J, Zakuth V et al (1999). Immune activation in non-treated suicidal major depression. Immunol Lett 67: 105-108.

Meyers CA, Scheibel RS, Forman AD (1991). Persistent neurotoxicity of systemically administered interferon-alpha. Neurology 41: 672-676.

Miller BJ, Buckley P, Seabolt W, Mellor A, Kirkpatrick B (2011). Meta-analysis of cytokine alterations in schizophrenia: clinical status and antipsychotic effects. Biol Psychiatry 70: 663-671.

Miller CM, Boulter NR, Ikin RJ, Smith NC (2009). The immunobiology of the innate response to Toxoplasma gondii. Int J Parasitol 39: 23-39.

Minderhoud IM, Samsom M, Oldenburg B (2007). Crohn's disease, fatigue, and infliximab: is there a role for cytokines in the pathogenesis of fatigue? World $\mathrm{J}$ Gastroenterol 13: 2089-2093.

Miyaoka H, Otsubo T, Kamijima K, Ishii M, Onuki M, Mitamura K (1999). Depression from interferon therapy in patients with hepatitis C. Am J Psychiatry 156: 1120.

Miyaoka T, Wake R, Furuya M, Liaury K, leda M, Kawakami K et al (2012). Minocycline as adjunctive therapy for patients with unipolar psychotic depression: an open-label study. Prog Neuropsychopharmacol Biol Psychiatry 37: 222-226.

Mommersteeg PM, Vermetten E, Kavelaars A, Geuze E, Heijnen CJ (2008). Hostility is related to clusters of $\mathrm{T}$-cell cytokines and chemokines in healthy men. Psychoneuroendocrinology 33: 1041-1050.

Moscicki EK (1994). Gender differences in completed and attempted suicides. Ann Epidemiol 4: 152-158.

Mossner R, Heils A, Stober G, Okladnova O, Daniel S, Lesch KP (1998). Enhancement of serotonin transporter function by tumor necrosis factor alpha but not by interleukin-6. Neurochem Int 33: 251-254.

Munkholm K, Brauner JV, Kessing LV, Vinberg M (2013). Cytokines in bipolar disorder vs. healthy control subjects: a systematic review and meta-analysis. J Psychiatr Res 47: 1119-1133.

Myint AM, Kim YK, Verkerk R, Scharpe S, Steinbusch H, Leonard B (2007). Kynurenine pathway in major depression: evidence of impaired neuroprotection. J Affect Disord 98: 143-151.

Myint AM, Schwarz MJ, Muller N (2012). The role of the kynurenine metabolism in major depression. J Neural Transm Nienna) 119: 245-251.
Na KS, Lee KJ, Lee JS, Cho YS, Jung HY (2014). Efficacy of adjunctive celecoxib treatment for patients with major depressive disorder: a meta-analysis. Prog Neuropsychopharmacol Biol Psychiatry 48: 79-85.

Nassberger L, Traskman-Bendz L (1993). Increased soluble interleukin-2 receptor concentrations in suicide attempters. Acta Psychiatr Scand 88: 48-52.

Nery FG, Monkul ES, Hatch JP, Fonseca M, Zunta-Soares GB, Frey BN et al (2008). Celecoxib as an adjunct in the treatment of depressive or mixed episodes of bipolar disorder: a double-blind, randomized, placebo-controlled study. Hum Psychopharmacol 23: 87-94.

Neuner P, Klosner G, Schauer E, Pourmojib M, Macheiner W, Grunwald C et al (1994). Pentoxifylline in vivo down-regulates the release of IL-1 beta, IL-6, IL-8 and tumour necrosis factor-alpha by human peripheral blood mononuclear cells. Immunology 83: 262-267.

Notarangelo FM, Wilson EH, Horning KJ, Thomas MA, Harris TH, Fang Q et al (2014). Evaluation of kynurenine pathway metabolism in Toxoplasma gondiiinfected mice: implications for schizophrenia. Schizophr Res 152: 261-267.

O'Connor JC, Lawson MA, Andre C, Moreau M, Lestage J, Castanon N et al (2009). Lipopolysaccharide-induced depressive-like behavior is mediated by indoleamine 2,3-dioxygenase activation in mice. Mol Psychiatry 14: 511-522.

O'Donovan A, Rush G, Hoatam G, Hughes BM, McCrohan A, Kelleher C et al (2013). Suicidal ideation is associated with elevated inflammation in patients with major depressive disorder. Depress Anxiety 30: 307-314.

Okun E, Griffioen K, Barak B, Roberts NJ, Castro K, Pita MA et al (2010). Toll-like receptor 3 inhibits memory retention and constrains adult hippocampal neurogenesis. Proc Natl Acad Sci USA 107: 15625-15630.

Okun E, Griffioen KJ, Mattson MP (2011). Toll-like receptor signaling in neural plasticity and disease. Trends Neurosci 34: 269-281.

Okusaga O, Yolken RH, Langenberg P, Lapidus M, Arling TA, Dickerson FB et al (2011). Association of seropositivity for influenza and coronaviruses with history of mood disorders and suicide attempts. J Affect Disord 130: 220-225.

Oquendo MA, Sullivan GM, Sudol K, Baca-Garcia E, Stanley BH, Sublette ME et al (2014). Toward a biosignature for suicide. Am J Psychiatry 171: 1259-1277.

Palagini L, Mosca M, Tani C, Gemignani A, Mauri M, Bombardieri S (2013). Depression and systemic lupus erythematosus: a systematic review. Lupus 22: 409-416.

Pandey GN, Rizavi HS, Ren X, Fareed J, Hoppensteadt DA, Roberts RC et al (2012). Proinflammatory cytokines in the prefrontal cortex of teenage suicide victims. J Psychiatr Res 46: 57-63.

Pandey GN, Rizavi HS, Ren X, Bhaumik R, Dwivedi Y (2014). Toll-like receptors in the depressed and suicide brain. J Psychiatr Res 53: 62-68.

Perez-Otano I, Schulteis CT, Contractor A, Lipton SA, Trimmer JS, Sucher NJ et al (2001). Assembly with the NR1 subunit is required for surface expression of NR3A-containing NMDA receptors. J Neurosci 21: 1228-1237.

Pollice PF, Rosier RN, Looney RJ, Puzas JE, Schwarz EM, O'Keefe RJ (2001). Oral pentoxifylline inhibits release of tumor necrosis factor-alpha from human peripheral blood monocytes: a potential treatment for aseptic loosening of total joint components. J Bone Joint Surg Am 83-A: 1057-1061.

Prandovszky E, Gaskell E, Martin H, Dubey JP, Webster JP, McConkey GA (2011). The neurotropic parasite Toxoplasma gondii increases dopamine metabolism. PloS One 6: e23866.

Price RB, Mathew SJ (2015). Does ketamine have anti-suicidal properties? Current status and future directions. CNS Drugs 29: 181-188.

Price RB, Nock MK, Charney DS, Mathew SJ (2009). Effects of intravenous ketamine on explicit and implicit measures of suicidality in treatment-resistant depression. Biol Psychiatry 66: 522-526.

Price RK, Risk NK, Haden AH, Lewis CE, Spitznagel EL (2004). Post-traumatic stress disorder, drug dependence, and suicidality among male Vietnam veterans with a history of heavy drug use. Drug Alcohol Depend 76 Suppl: S31-S43.

Raison CL, Rutherford RE, Woolwine BJ, Shuo C, Schettler P, Drake DF et al (2013). A randomized controlled trial of the tumor necrosis factor antagonist infliximab for treatment-resistant depression: the role of baseline inflammatory biomarkers. JAMA Psychiatry 70: 31-41.

Ramamoorthy S, Ramamoorthy JD, Prasad PD, Bhat GK, Mahesh VB, Leibach FH et al (1995). Regulation of the human serotonin transporter by interleukin-1 beta. Biochem Biophys Res Commun 216: 560-567.

Renault PF, Hoofnagle JH, Park Y, Mullen KD, Peters M, Jones DB et al (1987). Psychiatric complications of long-term interferon alfa therapy. Arch Intern Med 147: 1577-1580.

Reus GZ, Jansen K, Titus S, Carvalho AF, Gabbay V, Quevedo J (2015). Kynurenine pathway dysfunction in the pathophysiology and treatment of depression: Evidences from animal and human studies. J Psychiatr Res 68: 316-328.

Roth TL, Zoladz PR, Sweatt JD, Diamond DM (2011). Epigenetic modification of hippocampal Bdnf DNA in adult rats in an animal model of post-traumatic stress disorder. J Psychiatr Res 45: 919-926. 
Roy A (2003). Characteristics of drug addicts who attempt suicide. Psychiatry Res 121: 99-103.

Sadovnick AD, Eisen K, Ebers GC, Paty DW (1991). Cause of death in patients attending multiple sclerosis clinics. Neurology 41: 1193-1196.

Savitz J, Preskorn S, Teague TK, Drevets D, Yates W, Drevets W (2012). Minocycline and aspirin in the treatment of bipolar depression: a protocol for a proof-ofconcept, randomised, double-blind, placebo-controlled, $2 \times 2$ clinical trial. BMJ Open 2: e000643.

Schnieder TP, Trencevska I, Rosoklija G, Stankov A, Mann JJ, Smiley J et al (2014). Microglia of prefrontal white matter in suicide. J Neuropathol Exp Neurol 73: 880-890.

Schwarcz R, Bruno JP, Muchowski PJ, Wu HQ (2012). Kynurenines in the mammalian brain: when physiology meets pathology. Nat Rev Neurosci 13: 465-477.

Schwieler L, Larsson MK, Skogh E, Kegel ME, Orhan F, Abdelmoaty S et al (2015). Increased levels of IL-6 in the cerebrospinal fluid of patients with chronic schizophrenia-significance for activation of the kynurenine pathway. J Psychiatry Neurosci 40: 126-133.

Serafini G, Montebovi F, Lamis DA, Erbuto D, Girardi P, Amore M et al (2015). Associations among depression, suicidal behavior, and quality of life in patients with human immunodeficiency virus. World J Virol 4: 303-312.

Simanek AM, Cheng C, Yolken R, Uddin M, Galea S, Aiello AE (2014). Herpesviruses, inflammatory markers and incident depression in a longitudinal study of Detroit residents. Psychoneuroendocrinology 50: 139-148.

Smolen JS, Weinblatt ME, Sheng S, Zhuang Y, Hsu B (2014). Sirukumab, a human anti-interleukin-6 monoclonal antibody: a randomised, 2-part (proof-of-concept and dose-finding), phase II study in patients with active rheumatoid arthritis despite methotrexate therapy. Ann Rheum Dis 73: 1616-1625.

Steiner J, Bielau H, Brisch R, Danos P, Ullrich O, Mawrin C et al (2008). Immunological aspects in the neurobiology of suicide: elevated microglial density in schizophrenia and depression is associated with suicide. J Psychiatr Res 42: 151-157.

Steiner J, Walter M, Gos T, Guillemin GJ, Bernstein HG, Sarnyai Z et al (2011). Severe depression is associated with increased microglial quinolinic acid in subregions of the anterior cingulate gyrus: evidence for an immune-modulated glutamatergic neurotransmission? J Neuroinflammation 8: 94.

Steptoe A(ed) (2007). Depression and Physical IIIness. Cambridge University Press: Cambridge.

Stone TW (1993). Neuropharmacology of quinolinic and kynurenic acids. Pharmacol Rev 45: 309-379.

Suarez EC, Lewis JG, Kuhn C (2002). The relation of aggression, hostility, and anger to lipopolysaccharide-stimulated tumor necrosis factor (TNF)-alpha by blood monocytes from normal men. Brain Behav Immun 16: 675-684.

Sublette ME, Galfalvy HC, Fuchs D, Lapidus M, Grunebaum MF, Oquendo MA et al (2011). Plasma kynurenine levels are elevated in suicide attempters with major depressive disorder. Brain Behav Immun 25: 1272-1278.

Substance Abuse and Mental Health Services Administration. Results from the 2013 National Survey on Drug Use and Health: Mental Health Findings, NSDUH Series H-49, HHS Publication No. (SMA) 14-4887. Substance Abuse and Mental Health Services: Rockville, MD, 2014. Available at http://www.samhsa.gov/data/sites/ default/files/NSDUHmhfr2013/NSDUHmhfr2013.pdf.

Tanaka Y, Martin Mola E (2014). IL-6 targeting compared to TNF targeting in rheumatoid arthritis: studies of olokizumab, sarilumab and sirukumab. Ann Rheum Dis 73: 1595-1597.

Tavares RG, Tasca Cl, Santos CE, Alves LB, Porciuncula LO, Emanuelli T et al (2002). Quinolinic acid stimulates synaptosomal glutamate release and inhibits glutamate uptake into astrocytes. Neurochem Int 40: 621-627.

Taylor MW, Feng GS (1991). Relationship between interferon-gamma, indoleamine 2,3-dioxygenase, and tryptophan catabolism. FASEB J 5: 2516-2522.

Tidemalm D, Runeson B, Waern M, Frisell T, Carlstrom E, Lichtenstein P et al (2011). Familial clustering of suicide risk: a total population study of 11.4 million individuals. Psychol Med 41: 2527-2534.

Tonelli LH, Stiller J, Rujescu D, Giegling I, Schneider B, Maurer K et al (2008). Elevated cytokine expression in the orbitofrontal cortex of victims of suicide. Acta Psychiatr Scand 117: 198-206.

Tookman AJ, Jones CL, DeWitte M, Lodge PJ (2008). Fatigue in patients with advanced cancer: a pilot study of an intervention with infliximab. Support Care Cancer 16: 1131-1140.

Torres-Platas SG, Cruceanu C, Chen GG, Turecki G, Mechawar N (2014). Evidence for increased microglial priming and macrophage recruitment in the dorsal anterior cingulate white matter of depressed suicides. Brain Behav Immun 42: 50-59.

Treatment. CfSA (2009). Addressing Suicidal Thoughts and Behaviors in Substance Abuse Treatment. HHS Publication No. (SMA): Rockville, MD, USA, 09-4381.
Umhau JC, George DT, Heaney RP, Lewis MD, Ursano RJ, Heilig M et al (2013). Low vitamin D status and suicide: a case-control study of active duty military service members. PloS One 8: e51543.

Urata Y, Koga K, Hirota Y, Akiyama I, Izumi G, Takamura M et al (2014). IL-1beta increases expression of tryptophan 2,3-dioxygenase and stimulates tryptophan catabolism in endometrioma stromal cells. Am J Reprod Immunol 72 496-503.

US National Institute of Health (2016). Clinical trials. Available at https://clinicaltrials.gov/.

Valkanova V, Ebmeier KP, Allan CL (2013). CRP, IL-6 and depression: a systematic review and meta-analysis of longitudinal studies. J Affect Disord 150: 736-744.

Vaswani M, Linda FK, Ramesh S (2003). Role of selective serotonin reuptake inhibitors in psychiatric disorders: a comprehensive review. Prog Neuropsychopharmacol Biolog Psychiatry 27: 85-102.

Ventorp F, Barzilay R, Erhardt S, Samuelsson M, Traskman-Bendz L, Janelidze S et al (2016). The CD44 ligand hyaluronic acid is elevated in the cerebrospinal fluid of suicide attempters and is associated with increased blood-brain barrier permeability. J Affect Disord 193: 349-354.

Walker AK, Budac DP, Bisulco S, Lee AW, Smith RA, Beenders B et al (2013). NMDA receptor blockade by ketamine abrogates lipopolysaccharide-induced depressive-like behavior in C57BL/6J mice. Neuropsychopharmacology 38: 1609-1616.

Wekking EM (1993). Psychiatric symptoms in systemic lupus erythematosus: an update. Psychosoma Medicine 55: 219-228.

WHO (2012). Disease and injury regional mortality estimates, 2000-2012.

WHO (2014). Preventing Suicide: A Global Imperative. World Health Organization.

Wilcox HC, Conner KR, Caine ED (2004). Association of alcohol and drug use disorders and completed suicide: an empirical review of cohort studies. Drug Alcohol Depend 76 Suppl: S11-S19.

Wohleb ES, Powell ND, Godbout JP, Sheridan JF (2013). Stress-induced recruitment of bone marrow-derived monocytes to the brain promotes anxietylike behavior. J Neurosci 33: 13820-13833.

World Health Organization (2011). Projections of mortality and causes of death, 2015 and 2030.

Wu MK, Huang TL, Huang KW, Huang YL, Hung YY (2015). Association between toll-like receptor 4 expression and symptoms of major depressive disorder. Neuropsychiatr Dis Treat 11: 1853-1857.

Xie LF, Chen PL, Pan HF, Tao JH, Li XP, Zhang YJ et al (2012). Prevalence and correlates of suicidal ideation in SLE inpatients: Chinese experience. Rheumatol Int 32: 2707-2714.

Yirmiya R, Pollak Y, Morag M, Reichenberg A, Barak O, Avitsur R et al (2000). Illness, cztokines, and depression. Ann NY Acad Sci 917: 478-487.

Yoshio T, Onda K, Nara H, Minota S (2006). Association of IgG anti-NR2 glutamate receptor antibodies in cerebrospinal fluid with neuropsychiatric systemic lupus erythematosus. Arthritis Rheum 54: 675-678.

Zakeri Z, Shakiba M, Narouie B, Mladkova N, Ghasemi-Rad M, Khosravi A (2012). Prevalence of depression and depressive symptoms in patients with systemic lupus erythematosus: Iranian experience. Rheumatol Int 32: 1179-1187.

Zanos P, Moaddel R, Morris PJ, Georgiou P, Fischell J, Elmer Gl et al (2016). NMDAR inhibition-independent antidepressant actions of ketamine metabolites. Nature 533: 481-486.

Zanos P, Piantadosi SC, Wu HQ, Pribut HJ, Dell MJ, Can A et al (2015). The prodrug 4-chlorokynurenine causes ketamine-like antidepressant effects, but not side effects, by NMDA/glycineb-site inhibition. J Pharmacol Exp Ther 355: 76-85.

Zarate CA Jr, Brutsche NE, Ibrahim L, Franco-Chaves J, Diazgranados N, Cravchik A et al (2012). Replication of ketamine's antidepressant efficacy in bipolar depression: a randomized controlled add-on trial. Biol Psychiatry 71: 939-946.

Zhang J, Terreni L, De Simoni MG, Dunn AJ (2001). Peripheral interleukin-6 administration increases extracellular concentrations of serotonin and the evoked release of serotonin in the rat striatum. Neurochem Int 38: 303-308.

Zhang Y, Leung DY, Richers BN, Liu Y, Remigio LK, Riches DW et al (2012). Vitamin D inhibits monocyte/macrophage proinflammatory cytokine production by targeting MAPK phosphatase-1. J Immunol 188: 2127-2135.

Zhu CB, Blakely RD, Hewlett WA (2006). The proinflammatory cytokines interleukin1 beta and tumor necrosis factor-alpha activate serotonin transporters. Neuropsychopharmacology 31: 2121-2131.

Zhu CB, Carneiro AM, Dostmann WR, Hewlett WA, Blakely RD (2005). p38 MAPK activation elevates serotonin transport activity via a trafficking-independent, protein phosphatase 2A-dependent process. J Biol Chem 280: 15649-15658. 